\title{
Early Antecedents of Adult Work Stress: Social-Emotional Competence and Anger in Adolescence
}

\author{
Sheila T. Fitzgerald, ${ }^{1,5}$ Kathleen M. Brown, ${ }^{2}$ John R. Sonnega, ${ }^{3}$ and Craig K. Ewart ${ }^{4}$
}

\begin{abstract}
Accepted for publication: July 12, 2004
We hypothesized that youth with elevated coronary heart disease (CHD) risk who exhibit diminished social-emotional competence and frequent anger in adolescence experience increased occupational stress after becoming adults. Perceived job control and support from coworkers in 57 young Black and White men and women were regressed on measures of social problem-solving skill (SPS) and anger arousal (AR) obtained 5 years earlier when participants were in high school. In models controlling for grade point average (GPA), SPS and GPA independently predicted coworker support in adulthood; anger in high school predicted diminished job control. These findings suggest that occupational stress may have identifiable social-emotional antecedents early in life.
\end{abstract}

KEY WORDS: job stress; adolescence; anger; social competence.

Chronic negative affect and prolonged exposure to stressful working conditions have been implicated as personal and environmental factors that may increase heart disease risk (Jonas and Lando, 2000; Schnall et al., 1998). Although emotional distress and job stress usually have been studied as separate phenomena, there is evidence that susceptibility to angry affect, involving difficulty in understanding and relating to other people, contributes to increased stress on the job (Jamner et al., 1991). Social-cognitive theorists hold that emotions, behavior, and the social environment influence each other through processes of "reciprocal causation"; individuals shape their interpersonal environments and in turn are affected by them (Bandura, 1978). Angry affect and behavior,

\footnotetext{
${ }^{1}$ Department of Environmental Health Sciences, Bloomberg School of Public Health, Johns Hopkins University, Baltimore, Maryland.

${ }^{2}$ Maryland Medical Research Institute, Maryland.

${ }^{3}$ Institute for Social Research, University of Michigan, Ann Arbor, Michigan.

${ }^{4}$ Department of Psychology, Center for Health and Behavior, Syracuse University, Syracuse, New York.

${ }^{5}$ To whom correspondence should be addressed at Department of Environmental Health Sciences, Bloomberg School of Public Health, Johns Hopkins University, Baltimore, Maryland; e-mail: sfitzger@jhsph.edu.
}

for example, may evoke negative responses from coworkers, and mistrust of others may impair job performance (Buss, 1987). This suggests that people who fail to develop critical social-emotional competencies early in life may be at risk for increased occupational stress, and its associated health risks such as hypertension and cardiovascular disease in adulthood (Schnall et al., 1998).

Support for a causal connection between a person's social-emotional style in youth and later job performance comes from longitudinal research that followed cohorts of children into adulthood (Caspi et al., 1987, 1989). Boys who were "ill-tempered" at $8-10$ years of age grew into adults who at ages 30 and 40 were described as irritable and moody. Their working lives were marked by erratic employment and downward occupational mobility. Ill-tempered girls became women whose lives followed a similar pattern. The investigators argued that mechanisms of "interactional continuity" may partly explain these findings; such continuity occurs when a person's style evokes predictable reactions from others that tend to sustain that interactional style, and thereby elicit the problem behavior pattern over the life course (Caspi et al., 1987, 1989). A second mechanism highlighted in this research is "cumulative continuity;" this occurs when a person's interactive style causes 
him or her to gravitate to social environments that strengthen the individual's personal style, and thus perpetuate the behavior pattern throughout life.

This research suggests that longitudinal assessment of youths during the transition from adolescence into young adult work roles is needed in order to identify critical social and emotional variables that might contribute to interactional and cumulative continuities that lead to heightened occupational stress. These processes have not been examined extensively by health researchers.

An ongoing study of job stress in young adults who (earlier as adolescents) had participated in cardiovascular health research enables us to examine possible connections between social-emotional skills in youth and later job stress. Measures of job stress in young adulthood, assessed in a sample of urban Black and White men and women, were examined in relation to measures of interpersonal skill and chronic anger (CA) that had been obtained when the study participants were in high school.

Since adolescents in the present study were employed predominantly in the service sector (Castillo et al., 1999) and employment within this sector is characterized by direct interaction with clients or customers (deCastro et al., 2004; Hochschild, 1983), we hypothesized that study participants who lacked important social skills or who reported frequent anger during high school would exhibit higher levels of job stress when employed as service workers after graduating. The Karasek demand-control model (Karasek, 1979) guided our analysis of job stress. This model predicts that adverse responses to psychological strain (e.g., anxiety, physical illness, depression, fatigue) occur when psychological job demands (working fast, hard, and with repetition of job tasks) are high and job control (lack of decision making and skill discretion) is low (Karasek and Theorell, 1990; Ohlson et al., 2001; Pickering et al., 1996; Schwartz et al., 1996). Johnson and Hall (1988) modified the model to include social support from coworkers and supervisors. While some studies demonstrated a moderating role for social support at high levels of job stress (Frese, 1999; Johnson et al., 1996), others show only an independent effect of social support on health (Hammar, 1990; Vermuellen and Mustard, 2000). We reasoned that the social support dimension would be an important job stress factor in service work that entails direct and continuing faceto-face interactions with customers. Additionally, angry adults have been found to exhibit higher levels of arousal at work, thus interfering with interactions with others (Jamner et al., 1991, 1993; Matthews et al., 1997) and, thus, we determined that CA as an adolescent may predict job strain in adulthood.

The dimension of social competence assessed in this study was "social problem solving skill (SPS), "defined as an adolescent's ability to generate potentially appropriate and effective social scripts for handling challenging interpersonal situations. This capability, which has been shown to be correlated with social adjustment and interpersonal competence in children and youth (Ford, 1982; Platt and Spivack, 1975; Spivack and Shure, 1974; Spivack et al., 1976); was assessed when study participants were in ninth or tenth grade. Chronic anger (CA) was defined in terms of the self-reported frequency and intensity of angry emotions assessed annually during each of the participants' 4 years of high school. Study hypotheses were tested by regressing job stress components as well as job dissatisfaction in young adulthood on the social skill and anger measures obtained in adolescence, using regression models that controlled for race and gender. To assess the specific contributions of high school SPS and CA to later job stress, the analyses controlled also for indices of school adjustment and academic performance during high school.

\section{METHODS}

\section{Participants}

Participants were 57 young working adults who previously had been identified during school-wide health screening assessments that were conducted when the participants were in Grades 9 or 10. These students had participated in Project Heart 1 (PH1), the first in a series of school-based studies of cardiovascular risk in urban adolescents conducted in Baltimore by Craig K. Ewart and his associates at the Johns Hopkins University. Descriptions of study design, recruitment, and participant characteristics have been published previously (Ewart et al., 1986; Ewart and Kolodner, 1993; Ewart et al., 1998). All participants had attended one of two public high schools offering magnet programs that drew students from all parts of the city.

Approximately 5 years later, after PH1 participants had left high school, Sheila T. Fitzgerald conducted a follow-up study of all participants who could be located. Eligibility requirements for the follow-up included past participation in PH1 and current employment, either part- or full-time. Participants were 
invited to take part in a study of occupational stress for "Project Heart alumni"; after obtaining approval from the Committee on Human Research, data collection was initiated. It was possible to contact 195 $(75 \%)$ of the original $260 \mathrm{PH} 1$ participants. Of those contacted, $43(22 \%)$ chose not to participate in further research, and $62(32 \%)$ were ineligible for the present work stress study because they were enrolled in a college, university, or vocational program and not currently employed. Additionally, 33 individuals $(37 \%)$ had not completed the present social skills measure in PH1 (this measure was introduced into PH1 as part of an ancillary substudy) and thus were eliminated from analysis. The 57 participants who participated in the present study thus represent $63 \%$ of the original PH1 sample who (a) could be contacted; (b) were eligible; and (c) had completed the social skills measure when in high school. The mean age of study participants was $19 \pm 1$ years; the sample included 14 Black women, 16 Black men, 13 White women, and 14 White men. All were employed in retail or service sector jobs; $45 \%$ worked full-time and $43 \%$ attended school on a full- or part-time basis. The average number of hours worked per week was $30 \pm 12 \mathrm{~h}$. In response to the statement "My job security is good," $66 \%$ strongly disagreed, $24 \%$ disagreed, and $10 \%$ agreed. Thirty-five $(61 \%)$ participants reported an annual salary of less than $\$ 10,000$, 18 (33\%) earned between \$10,000-20,000, 4 (6\%) earned more than $\$ 20,000$ annually. The work stress assessments were performed at the Johns Hopkins Medical Institutions; participants were reimbursed $\$ 10$ to cover expenses incurred by attending the assessment session.

\section{Social-Emotional Predictors (High School)}

Social Problem Solving Skill (SPS) was assessed with a modified version of the Means-Ends Problem Solving (MEPS) procedure, developed originally by Platt and Spivack (Platt and Spivack, 1975; Spivack and Shure, 1974) for research with young children and subsequently modified by Ford (1982) for research with high school students. The MEPS measures SPS ability by means of the "open-middle" story completion technique. The participant listens to an interviewer read aloud the beginning of a story that describes a typical social situation, such as attempting to make new friends on the first day of school. The narrator reads the story's beginning (e.g., a student enters the school building) and then reads the story's ending (e.g., the student has succeeded in making (a) number of friends); the participant then is invited to "fill in the middle" by inventing a narrative that connects the initiating set of circumstances with the specified ending. To complete the task, the participant must draw upon a store of personal knowledge concerning how one goes about making friends. Participants' narratives are recorded on audiotape and, after being transcribed, are coded by trained raters. The MEPS stories used in this study included three social scenarios developed for use with adolescents (Ford, 1982); they included situations such as making new friends at school, achieving reconciliation after a fight with a close friend, and influencing a group of one's peers. Research with the modified MEPS, and similar skill-assessment procedures, has shown that performance scores predict concurrent and prospective indices of social-emotional competence, interpersonal behavior, and adjustment (Crick and Dodge, 1994; Ford, 1982).

The participants' transcribed responses (problem solutions) were rated for "effectiveness" using a 5 -point Likert scale $(1=$ not at all effective; 5 $=$ very effective $)$ by trained raters. Two raters independently scored the MEPS transcripts; raters followed a coding manual that provided examples of poor, moderately effective, and very effective social scripts for each MEPS situation (Sonnega, 1996). For example, a "very effective" group influence script would include elements such as "listen to others in the group before speaking," "try to understand and summarize what others are saying," "show appreciation for others' views," "offer to perform a service for the group." Thirty of the transcripts were rated by both raters; correlations between the raters scores exceeded $r=0.85$. A single SPS skill score was generated for each participant by computing the mean of the MEPS narrative effectiveness ratings for that individual. The construct validity of the resulting SPS skill score measure was assessed by computing the correlation between the SPS scores and teacher's ratings (based on classroom impressions) of each participant's competence in social communication, selfassertion, peer leadership, and popularity (Sonnega, 1996). The correlation between the SPS scores and the sum of the teacher ratings was statistically significant $(r=0.23, p<0.05)$, supporting the construct validity of the SPS. Chronic Anger (CA) during high school was defined as the mean of the scores on the Anger Arousal (AR) scale that were obtained during successive annual assessments when participants were in Grades 10, 11, and 12. The AR scale is a 
10-item questionnaire that measures the frequency and intensity of angry emotions (Ewart and Kolodner, 1994). Adapted originally from the Multidimensional Anger Inventory (Siegel, 1986), the AR scale has acceptable internal consistency, as indicated by a Cronbach's alpha of 0.85 , and 1-month test-retest reliability of $r=0.75$ (Ewart and Kolodner, 1994).

Academic Performance and Adjustment during high school were assessed with two indices. High School Grade Point Average (GPA), defined as the mean of all semester grades earned during all years of high school, and school Absences, defined as the mean number of days per semester when a student was recorded as being absent from school. This information was obtained from school records.

\section{Job Characteristics (After High School)}

Components of the Job Strain Model were measured with the Job Content Questionnaire (JCQ; Karasek et al., 1998) which measures psychosocial risk factors and social structure in the work environment. The JCQ is a questionnaire designed to measure the nature of work tasks (demands, decision making opportunities, and social interactions) as perceived by the study subject. We planned to utilize three scales of the JCQ in this study: job control (comprised of skill discretion and decision authority), social support (comprised of coworker and supervisor support), and psychological job demands. However, the psychological job demands scale could not be included in the analysis due to its low internal consistency $(\alpha=0.47)$. Eliminating the psychological job demands scale made it impossible to calculate job strain, which is defined as a composite of job demand and job control. Our previous study of adolescents, in which we examined the psychometric characteristics of the JCQ, also found that the internal consistency of the psychological demands scale was unacceptably low (Fitzgerald et al., 2003).

Nine items assessed Job Control (e.g., "My job requires me to learn new things," "My job allows me to make decisions on my own"). Coefficient alpha for this scale was in the acceptable range $(\alpha=0.82)$. Dimensions of coworker (e.g., "People I work with take a personal interest in me") and supervisor support (e.g., "My supervisor is helpful at getting the job done") included eight items to measure Total Job Support with an acceptable level of internal consistency $(\alpha=0.89)$.
Work Status was coded as working full-time ( $\geq 40 \mathrm{~h}$ per week) or part-time ( $<40 \mathrm{~h}$ per week). Job title and occupation (Department of Labor, 1990), job stability, hours worked, and income was assessed by means of a questionnaire.

\section{Statistical Analysis}

We first performed univariate analyses to determine if the variables were normally distributed and to see if data transformation was necessary. Bivariate relationships among the predictor variables (SPS, AR, GPA, Absences) and between the work stress outcome variables after high school (Job Control and Social Support) were examined using Pearson correlations.

The primary analyses tested the hypothesis that SPS and CA during high school would predict job stress in young adulthood after controlling for indices of academic performance. These predictions were tested by regressing each job stress component (Job Control and Social Support) on one of the high school performance variables (GPA, Absences) followed by one of the social-emotional predictors (SPS score, CA). The SPSS version 10.0 statistical computer software was used to perform these regressions. Analyses of the range of scores on the variables under study include the following: GPA $(M=80.27$, $\mathrm{SD}=5.51)$; School Absences $(M=7.52, \mathrm{SD}=5.53)$; Job Control $(M=25.16, \mathrm{SD}=4.57)$, and Job Social Support $(M=24.36, \mathrm{SD}=4.06)$.

\section{RESULTS}

Univariate analyses on the dependent variables indicated that job control and total job support were normally distributed. Before performing the regression analyses, we examined the degree of association between the social-emotional and school performance variables. Inspection of Pearson correlations revealed that SPS scores and CA scores were not significantly correlated with each other, nor were they correlated with either of the school performance variables (all correlation coefficients were lower than $r=0.10)$. Not surprisingly, however, there was a significant inverse relationship between high school GPA and Absences from school $(r=-0.31$, $p<0.05$ ). Chronic anger did not predict workplace support, and all interactions were nonsignificant.

We also tested for possible race and gender differences in the levels of the study variables. This was 
Table I. Regression of Job Support in Young Adulthood on Social Problem Solving Skill Assessed in Grade Ninth or Tenth, and High School Grade Point Average (GPA)

\begin{tabular}{lccc}
\hline \multicolumn{1}{c}{ Predictor } & $\beta$ & $t$ & $p<$ \\
\hline High school GPA & 0.37 & 3.29 & 0.002 \\
Social problem-solving skill & 0.40 & 3.55 & 0.001 \\
\hline
\end{tabular}

accomplished by regressing each of the six study variables on race, gender, and the race by gender interaction term. Results of these analyses disclosed no statistically significant main effects or interaction effects, suggesting that the levels of the study variables did not differ significantly by race and/or gender.

\section{Multiple Regression Analyses}

Results of the regression of Job Support (JS) scores on high school SPS scores after controlling for high school GPA are shown in Table I. The level of perceived support from one's coworkers and supervisors in early adulthood was positively associated with a worker's prior GPA throughout high school and his or her level of SPS skill assessed in Grade 9 or 10. A second regression model, in which Absences replaced GPA, was run also. Results of this second model (not shown) indicated that high school Absences were not significantly associated with JS scores in young adulthood; the statistically significant association between JS scores and SPS scores in this second analysis was virtually identical to that shown in Table I. Similar regression models assessed the relationship between high school CA and later job support, after controlling for GPA or absences. In these analyses, only high school GPA predicted young adult JS scores $(p<0.002)$; neither CA scores nor Absences predicted job support in early adulthood.

Results of the regression of Job Control (JC) on high school AR after controlling for high school GPA are shown in Table II. The degree of control that a worker was able to exercise over the work process in early adulthood was negatively associated

Table II. Regression of Job Control in Young Adulthood on Chronic Anger Assessed During High School, and High School Grade Point Average (GPA)

\begin{tabular}{lccc}
\hline \multicolumn{1}{c}{ Predictor } & $\beta$ & $t$ & $p<$ \\
\hline High school GPA & 0.21 & 1.68 & 0.11 \\
Anger arousal & -0.27 & -2.14 & 0.04 \\
\hline
\end{tabular}

with the worker's frequency and intensity of anger throughout high school. Academic performance (GPA) in high school did not predict young adult job control. A second regression model, in which Absences replaced GPA, was run also. Results of this second model (not shown) indicated that high school Absences were not significantly associated with job control in young adulthood; the statistically significant association between JC scores and CA scores in this second analysis was virtually identical to that shown in Table II. Similar regression models assessed the relationship between high school SPS and later JC, after controlling for high school GPA or Absences. High school SPS scores were not significantly associated with JC scores in either model. As was the case in the regressions of JC on CA, neither high school GPA nor Absences predicted JC outcomes in early adulthood.

\section{DISCUSSION}

Present findings raise the possibility that occupational stress, an important potential contributor to coronary heart disease (CHD) risk, may have identifiable social-emotional antecedents early in life. Results are generally compatible with the hypothesis that SPS deficits and anger arousal in adolescence could predispose some individuals to experience heightened job stress later, when they enter the work place. Young adults of both genders who had performed poorly on the MEPS test of SPS ability when in ninth or tenth grade reported that they received less support from their coworkers and supervisors than did peers who had exhibited more robust SPS skills at 14 years of age. Young women and men who had experienced frequent and intense anger while in high school reported diminished ability to control work processes and routines, relative to peers who had experienced less anger during adolescence. Together, these findings provide preliminary support for the hypothesis that social-emotional competence early in life and subsequent exposure to stressful work environments may be related.

As predicted, overall social support (coworker and supervisor) and job control in young adulthood were related to earlier academic performance. Students who had earned lower grades in high school later reported receiving less support from their work colleagues than did students who had performed well academically. It appears that personal and social problems that impair academic performance during 
the high school years may adversely affect work opportunities and roles later in life, a process consistent with Caspi et al.'s notion of "cumulative continuity" (Caspi et al., 1989). The number of absences from school did not predict later job control, however. Support from one's coworkers and supervisors was predicted by earlier manifestations of academic ability, but not by the index of impaired school attendance. The use of magnet schools to recruit study participants may partly explain this; students who develop attendance problems may be required to leave the magnet school and return to their local "zone" school. Such participants would have been lost to the study, since they no longer attended the magnet school.

It is interesting to note that SPS skill at age 14, assessed by means of a verbal story completion procedure, predicted young adult overall job social support even after controlling for academic ability as reflected in the average of all grades earned during a youth's high school career. This finding suggests that the modified MEPS task used here may tap aspects of social skill that are not completely redundant with the intellectual and motivational qualities that contribute to academic success; it is possible that these distinct social skill components are independently associated with protection against job stress in early adulthood. Prior research on social problem solving abilities has indicated that the specific social skills measured by tests such as the MEPS are largely independent of the specific intellectual abilities measured by tests of general intelligence (D'Zurilla and Sheedy, 1991).

The observed associations also appear to be compatible with processes of "interactional continuity" (Caspi et al., 1989). The link between SPS skills in adolescence and job support in early adulthood may imply that young workers who are skilled in developing interpersonal ties may be able to create supportive occupational environments that protect them from job stress. Conversely, young workers whose irritability makes them difficult to work with may be assigned to perform highly routinized tasks or relegated to constrained work roles, in which they exercise limited control. Alternative explanations are possible as well. For example, individuals who are able to generate effective social scripts may be more inclined to perceive their social environments as supportive. And individuals who are chronically angry may be predisposed to construe their work roles and tasks as offering them scant opportunity for personal control. Even though job stress is measured in jobs acquired shortly after high school graduation, our findings suggest that job stress occurs among young workers as a result of CA and limited SPS. This very preliminary study suggests that future studies of job stress be conducted in young workers to identify the antecedents as well as the implications for physical health.

The analyses presented in this report have several important limitations. First, PH1 was not designed as a longitudinal investigation of the early antecedents of occupational stress; data needed to establish more direct connections between behavior during adolescence and later work roles, tasks, and environments are not available in this sample. Second, while the correlations between the high school predictor variables and the job stress outcomes were in the predicted direction, results were somewhat mixed. For example, CA during high school did not predict job support, and SPS skill did not predict job control. It is possible that the types of social skills assessed by the MEPS test may be more relevant to developing supportive relationships in the work setting than to the other components of job stress. It should be noted also that, although SPS as measured here is correlated with other indices of social-emotional competence, the MEPS procedure does not measure social behavior directly. Moreover, CA was measured by self-report, which may be subject to reporting biases. Studies using multimodal assessments of these important constructs would be helpful.

Another limitation of the study is the inability to assess relationships between the social-emotional predictors and the psychological demands of work, due to the low internal consistency of the Psychological Job Demand scale. This study is the first to apply the Karasek model to young workers in service sector occupations; further modifications of the JCQ may be needed to increase the psychometric properties of the Psychological Job Demand scale in young working populations. Even so, we note that occupational stress researchers have found that Job Control predicts new cases of CHD more strongly than does the Job Demand component of the JCQ (Bosma et al., 1998; Karasek et al., 1998; Marmot et al., 1999).

Despite multiple attempts to recruit the original study subjects into our follow-up, we were limited by failure of participants to meet study eligibility and a high refusal rate. These attrition patterns may have biased our results in that those who chose not to participate or were not employed or enrolled in postgraduate education may have better or worse adjustment than those enrolled in our study. 
Questions of generalizability must be addressed also. Note that participants in the present study lived in low SES urban neighborhoods, had attended magnet schools, were at increased hypertension risk, and were willing to participate in health screening and follow-up studies. Moreover, the majority $(70 \%)$ did not enjoy "good" job security. Finally, job stress was assessed cross-sectionally in this study and, as a result, the magnitude and duration of exposure to the components of chronic job stress was not determined.

A large proportion of the jobs available to young urban adults increasingly are found in the service sector (Fitzgerald and Laidlaw, 1995). These highdemand, low-control jobs, involving frequent interactions with customers, coworkers, and supervisors, present interpersonal challenges that have the potential to evoke anger and other negative emotions and, thereby, to increase cardiovascular disease risk (Greenlund et al., 1995). This tendency may be related to deficient social emotional competence. Thus, the association between anger arousal in adolescence and low job control in young adulthood identified in this study may be an early marker for the later development of job stress and cardiovascular disease in middle age (Karasek and Theorell, 1990; Schnall et al., 1994; Theorell and Karasek, 1996). Present findings suggest a need for carefully designed longitudinal studies that investigate the early personal, behavioral, and environmental antecedents of health damaging occupational stress.

\section{ACKNOWLEDGMENTS}

This research was supported by Grants R01HL36298 and R01-HL52080 to Craig K. Ewart, and by Grants 3R01- HL45139-02S1 and R01-OH03736 to Sheila T. Fitzgerald.

We thank Anne Carusi, Principal of Western High School, and Ian Cohen, Director of the Baltimore Polytechnic Institute, and their teaching staffs, for their assistance in implementing this study. We also thank Paul Plott who managed the data collection process.

\section{REFERENCES}

Bandura, A. (1978). The self system in reciprocal determinism. Am. Psychol. 33: 344-358.

Bosma, H., Peter, R., Siegrist, J., and Marmot, M. (1998). Two alternative job stress models and the risk of coronary heart disease. Am. J. Public Health 88: 68-74.
Buss, D. M. (1987). Selection, evocation, and manipulation. $J$. Pers. Soc. Psychol. 53: 1214-1221.

Caspi, A., Bem, D. J., Elder, G. H., Jr. (1989). Continuities and consequences of interactional styles across the life course. $J$. Pers. 57: 375-406.

Caspi, A., Elder, J. G. H., and Bem, D. J. (1987). Moving against the world: Life-course patterns of explosive children. Dev. Psychol. 23: 308-313.

Castillo, D. N., Davis, L., and Wegman, D. H. (1999). Young workers. Occup. Med.: State Art Rev. 14(3): 519-536.

Crick, N. R., and Dodge, K. A. (1994). A review and reformulation of social information-processing mechanisms in children's social adjustment. Psychol. Bull. 115: 74-101.

D'Zurilla, T. J., and Sheedy, C. F. (1991). Relation between social problem-solving ability and subsequent level of psychological stress in college students. J. Pers. Soc. Psychol. 61: 841846.

deCastro, A. B., Agnew, J., and Fitzgerald, S. T. (2004). Emotional labor: Relevant theory for occupational health practice in post-industrial America. AAOHN J. 52: 109-115.

Ewart, C. K., Harris, W. L., Zeger, S., and Russell, G. A. (1986). Diminished pulse pressure under mental stress characterizes normtensive adolescents with parental high blood pressure. Psychosom. Med. 48: 489-501.

Ewart, C. K., and Kolodner, K. B. (1993). Predicting ambulatory blood pressure during school: Effectiveness of social and nonsocial reactivity tasks in black and white adolescents. Psychophysiology 30: 30-38.

Ewart, C. K., and Kolodner, K. B. (1994). Negative affect, gender, and expressive style predict elevated ambulatory blood pressure in adolescents. J. Pers. Soc. Psyc. 66(3): 596605.

Ewart, C. K., Rohm-Young, D., and Hagberg, J. M. (1998). Effects of school-based aerobic exercise on blood pressure in adolescent girls at risk for hypertension. Am. J. Public Health 88(6): 949-951.

Fitzgerald, S. T., and Laidlaw, A. D. (1995). Adolescents and work: Risk and benefits of teenage employment. AAOHN J. 43(4): 185-189.

Frese, M. (1999). Social support as a moderator of the relationship between work stressors and psychological dysfunctioning: A longitudinal study with objective measures. J. Occup. Health Psychol. 4: 179-192.

Ford, M. E. (1982). Social competence and social cognition in adolescence. Dev. Psychol. 18: 323-340.

Greenlund, K. J., Liu, K., Knox, S., McCreath, H., Dyer, A., and Gardin, J. (1995). Psychosocial work characteristics and cardiovascular disease risk factors in young adults: The CARDIA study. Soc. Sci. Med. 41(5): 717-723.

Hammar, N., Alfredsson, L., and Johnson, J. V. (1990). Job strain, social support at work and incidence of myocardial infarction. Occup. Environ. Med. 55: 548-553.

Jamner, L. D., Shapiro, D., and Goldstein, I. H. U. G. (1991). Ambulatory blood pressure and heart rate in paramedics: Effects of cynical hostility and defensiveness. Psychosom. Med. 53: 393-406.

Jamner, L. D., Shapiro, D., Hui, K. K., Oakley, M. E., and Lovett, M. (1993). Hostility and anger differences between clinic, self-determined, and ambulatory blood pressure. Psychosom. Med. 66: 203-211.

Johnson, J. V., and Hall, E. M. (1988). Job strain, work place social support, and cardiovascular disease: A cross-sectional study of a random sample of the Swedish working population. Am. J. Public Health. 78: 1336-1342.

Johnson, J. V., Stewart, W., Hall, E. M.,Friedlund, P., and Theorell, T. (1996). Combined effects of job strain and social isolation on cardiovascular disease morbidity and mortality in a random sample of Swedish male population. Am. J. Public Health 86: 324-331. 
Jonas, B. S., and Lando, J. F. (2000). Negative affect as a prospective risk factor for hypertension. Psychosom. Med. 62: 188196.

Karasek, R. (1979). Job demands, job decision latitude, and mental strain: Implications for job redesign. Adm. Sc. Quar. 24: 285307.

Karasek, R., and Theorell, T. (1990). Healthy work: Stress, productivity and the reconstruction of working life. Basic Books, New York.

Karasek, R., Brisson, C., Kawakami, N., Houtman, I., Bongers, P., and Amick, B. (1998). The job content questionnaire (JCQ): An instrument for internationally comparative assessments of psychosocial job characteristics. J. Occup. Health Psychol. 3: 322-355.

Marmot, M., Siegrist, J., Theorell, T., and Feeney, A. (1999). Health and the psychosocial environment at work. In Marmot, M., and Wilkinson, R. G. (Eds.), Social Determinants of Health, Oxford University Press, Oxford, pp. 105-131.

Matthews, K., Gump, B. B., Block, D. R., and Allen, M. T. (1997). Does background stress heighten or dampen children's cardiovascular responses to acute stress? Psychom. Med. 59: 488-496.

Ohlson, C.-G., Soderfeld, M., Soderfeldt, B., Jones, I., and Theorell, T. (2001). Stress markers in relation to job strain in human service organizations. Psychother. Psych. 70: 268-275.

Pickering, T. G., Devereux, R. B., James, G. D., Gerin, W., Landsbergis, P., Schnall, P. L., and Schwartz, J. E. (1996). Environmental influences on blood pressure and the role of job stain. J. Hyper. (suppl.) 14: S179-S185.
Platt, J. J., and Spivack, G. (1975). Measures of Interpersonal Cognitive Problem Solving for Adults and Adolescents (Manual). Philadelphia.

Schnall, P. L., Lansbergis, P. A., Baker, D. (1994). Job strain cardiovascular disease. Annu. Rev. Public Health. 15: 381-411.

Schnall, P. L., Schwartz, J. E., Landsbergis, P. A., Warren, K., and Pickering, T. O. (1998). A longitudinal study of job strain and ambulatory blood pressure: Results from a three-year followup. Psychosom. Med. 60: 697-706.

Schwartz, J. E., Pickering, T. G., and Landsbergis, P. A. (1996). Work-related stress and blood pressure: Current theoretical models and considerations from a behavioral medicine perspective. J. Occ. Health Psych. 1: 287-310.

Siegel, J. M. (1986). The Multidimensional Anger Inventory. J. Per. Soc. Psych. 51: 191-200.

Sonnega, J. R. (1996). A Social Competence Analysis of Trait Anger in Adolescents at Risk for Hypertension, Johns Hopkins University, Baltimore, MD.

Spivack, G., Platt, J. J., and Shure, M. B. (1976). The ProblemSolving Approach to Adjustment, Jossey-Bass, San Francisco.

Spivack, G., and Shure, M. B. (1974). Social Adjustment in Young Children: A Cognitive Approach to Solving Real Life Problems, Jossey-Bass, San Francisco.

Theorell, T., and Karasek, R. (1996). Current issues relating to psychosocial job strain and cardiovascular disease research. J. Occ. Health Psych. 1: 9-26.

Vermeulen, M., and Mustard, C. (2000). Gender differences in job strain, social support at work, and psychological distress. $J$. Occ. Health Psych. 5: 428-440. 